\title{
High-Energy Flux Density Extracorporeal Shock Wave Therapy Versus Traditional Physical Therapy Modalities in Myofascial Pain Syndrome: A Randomized-controlled, Single-Blind Trial
}

\author{
Ömer GEZGIINASLAN@ Sevgi GÜMÜŞ ATALAY®] \\ Department of Physical Therapy and Rehabilitation, University of Health Sciences \\ Ümraniye Training and Research Hospital, İstanbul, Turkey
}

\begin{abstract}
Objectives: This study aims to investigate the effects of extracorporeal shock wave therapy (ESWT) on pain, sleep, fatigue, disability, depression, and quality of life (QoL) in patients with myofascial pain syndrome (MPS).

Patients and methods: Between March 2018 and September 2018, a total of 94 patients (16 males, 78 females; mean age $44.2 \pm 11.94$ years; range, 19 to 74 years) with the diagnosis of MPS were included in the study. The patients were divided into two groups. The treatment group consisted of 49 patients and a total of seven sessions of high-energy flux density ESWT (H-ESWT) $\left(0.26 \mathrm{~mJ} / \mathrm{mm}^{2}\right)$ were given with three days interval. The control group consisted of 45 patients and the treatment of hot pack, transcutaneous electrical nerve stimulation, and ultrasound was given for five days for two weeks. At baseline and one month after treatment, the visual analog scale (VAS), Short Form-36 (SF-36), Pittsburgh Sleep Quality Index (PSQI), Functional Assessment of Chronic Illness Therapy (FACIT)-Fatigue Scale, Neck Disability Index (NDI), and Beck Depression Inventory (BDI) scores were compared between the groups.

Results: There were no statistically significant differences in the age, sex, demographic characteristics, and baseline VAS, SF- $36, \mathrm{NDI}, \mathrm{BDI}, \mathrm{FACIT}$, and PSQI scores between the groups ( $p>0.05$ ). In the ESWT group, there was a statistically significant decrease in the VAS, SF- $36, \mathrm{NDI}, \mathrm{BDI}, \mathrm{FACIT}$, and PSQI scores after treatment compared to the baseline scores, while only the SF-36 subscale scores were statistically significantly higher ( $p<0.05)$. There was a statistically significant correlation between the VAS and SF-36 scores and the BDI, NDI, FACIT and PSQI scores after the treatment.

Conclusion: Our study results suggest that H-ESWT is more effective than traditional physical therapy methods on pain, QoL, sleep, fatigue, depression, and disability in patients with MPS.

Keywords: Disability, extracorporeal shock wave therapy, myofascial pain syndrome, quality of life, sleep.
\end{abstract}

Myofascial pain syndrome (MPS) is a common musculoskeletal syndrome characterized by muscle stiffness, typical pain, intramuscular taut band, local twitch response, and hyperirritable muscle fibers known as myofascial trigger points (MTrPs). ${ }^{1,2}$ Upper trapezius trigger points are the most frequent causes of pain in patients with MPS. ${ }^{3,4}$ Fischer described the most affected hyperirritable points on the upper trapezius muscle. The pathophysiology of MPS has been thought to be due to shortened muscle fibers and taut bands as a result of increased calcium influx to the muscular fibers or increased acetylcholine secretion in motor end plates. ${ }^{5}$

A growing number of evidence-based studies have suggested treatment modalities for MPS including trigger point injection (TPI), dry needling, stretching, ultrasound (US), manual therapies, superficial hot pack (HP) and cold pack, medical treatments, transcutaneous electrical

Received: March 13, 2019 Accepted: April 21, 2019 Published online: June 25, 2019

Correspondence: Ömer Gezginaslan, MD. SBÜ Ümraniye Eğitim ve Araştırma Hastanesi Fiziksel Tıp ve Rehabilitasyon Kliniği, 34764 Ümraniye, İstanbul, Turkey. Tel: +90 530 - 4493466 e-mail: omergezginaslan@hotmail.com 
nerve stimulation (TENS), and massage. ${ }^{6-15}$ Extracorporeal shock wave therapy (ESWT) is a novel, non-invasive therapeutic modality for musculoskeletal system diseases such as calcific tendinopathies, plantar fasciitis, and lateral and medial epicondylitis ${ }^{16-19}$ as well as for MPS. ${ }^{20-24}$ Although there are some theories proposed, the mechanism of action of ESWT on MPS still remains to be elucidated. The Energy Crisis Hypothesis may explain how ESWT affects other diseases. ${ }^{25,26}$ The ESWT mainly exerts its effects by increasing perfusion of damaged ischemic tissues, increasing vascularization and changing pain stimuli in ischemic tissues via increasing intake of calcium. In this study, we aimed to investigate the effects of ESWT on pain, sleep, fatigue, disability, depression, and quality of life (QoL) in patients with MPS.

\section{PATIENTS AND METHODS}

This prospective, randomized, single-blind clinical study was conducted at musculoskeletal outpatient clinic of University of Health Sciences Ümraniye Training and Research Hospital between March 2018 and September 2018. A total of 94 patients (16 males, 78 females; mean age $44.2 \pm 11.9$ years; range, 19 to 74 years) with the diagnosis of MPS were included. Inclusion criteria were as follows: having a diagnosis of MPS according the criteria defined by Travel and Simons; ${ }^{27}$ persistent myofascial pain at trapezius levator scapulae, supraspinatus, or infraspinatus at least for six months as assessed by a visual analog scale (VAS) score of $>3 ;^{28}$ and having at least three MTrPs. Exclusion criteria were as follows: no prior treatment including ESWT within the last six months; having a diagnosis of other spinal diseases such as cervical spinal stenosis, spondylolisthesis, cervical hernias, cervical radiculopathy, or myelopathy; previous cervical or lumbar spinal surgery; malignancy; other inflammatory diseases; pregnancy; having a cardiac pacemaker; local infections; severe cardiac or renal diseases; or neurological deficits involving lower extremities. To rule out other spinal diseases, all patients underwent detailed physical and neurological examinations. In addition, cervical, thoracic, and lumbar anteroposterior and lateral plain radiographs and cervical, thoracic, and lumbar magnetic resonance imaging scans were obtained. The study protocol was approved by the University of Health Sciences Ümraniye Training and Research Hospital Ethics Committee. A written informed consent was obtained from each patient. The study was conducted in accordance with the principles of the Declaration of Helsinki.

The patients were divided into two groups. The treatment group (ESWT group) consisted of 49 patients and a total of seven sessions of high-energy flux density ESWT (H-ESWT) $\left(0.26 \mathrm{~mJ} / \mathrm{mm}^{2}\right)$ were given with three days interval. The traditional treatment group (control group) consisted of age- and sex-matched 45 patients and the treatment of HP, TENS, and US was given for five days for two weeks. Data including baseline demographic characteristics of both groups were recorded. The study flow chart is shown in Figure 1.

We used G*Power version 3.1.2 (HeinrichHeine-Universität Düsseldorf, Düsseldorf, Germany) to calculate the sample size. To estimate

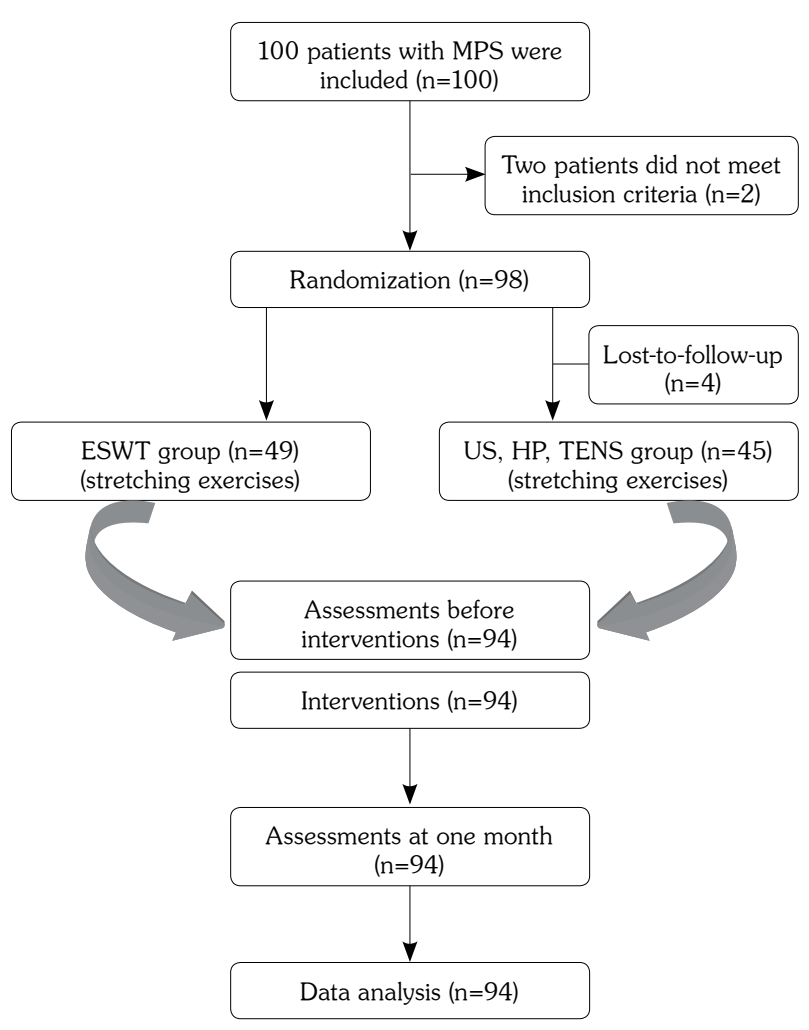

Figure 1. Study flow chart.

MPS: Myofascial pain syndrome; ESWT: Extracorporeal shock wave therapy; US: Ultrasound; HP: Hot pack; TENS: Transcutaneous electrical nerve stimulation. 
the effect of ESWT, we used data from a pilot study $^{29}$ in which ESWT affected short form-36 (SF-36) physical function subscale scores (standard deviation $[S D]=21.3$ ) which corresponded to an estimated effect size of 0.68545 .

Based on an alpha value of 0.05 for statistical significance, a total of 37 patients are required in each group to achieve $80 \%$ statistical power. Thus, a total of 74 patients were planned to be recruited in both groups. Assuming a dropout of 15\%, 100 patients were expected to be included.

The patients were divided into two groups as the ESWT group and control group by random selection using sequentially numbered, opaque, sealed envelopes. The investigators who assessed pre- and post-treatment measurements were not allowed to attend to the intervention period and were blinded to group allocation.

All pre- (at baseline) and post-treatment (at one month) measurements were evaluated by a single investigator. The VAS was used to evaluate pain severity. Scores of this scale range from 0 to 10 ; while 0 indicates no pain, 10 indicates unbearable pain. All patients were asked to rate their pain level.

The QoL was evaluated using the SF-36 which consists of eight subscales and 36 items. It is used to evaluate physical and mental health of the patients. Limitation of physical activity was assessed by physical functioning (PF), limitations of daily activities by difficulty in physical role (DPR), pain severity by bodily pain, rating of health by general health, energy and fatigue by vitality, limitations of daily activities by social functioning, and limitation of regular daily activities by difficulty in emotional role and mental health. ${ }^{30}$

The sleep quality and sleep disturbances within the last month were evaluated using the Pittsburgh Sleep Quality Index (PSQI). This scale ranges from 0 to 21 and higher scores indicate worse sleep quality. ${ }^{31}$

The Functional Assessment of Chronic Illness Therapy (FACIT)-Fatigue Scale was used to assess whether the patients were able to maintain their daily activities. It ranges from 0 to 52 and higher scores indicate lower energy and difficulty in daily activities. $^{32}$

The Neck Disability Index (NDI) was used to evaluate disability related to neck pain. This scale ranges from 0 to 50 and higher scores indicate more self-rated disability. The validity and reliability studies of the Turkish version of the NDI have been shown. ${ }^{33}$

The Beck Depression Inventory (BDI) was used to assess severity of depression. It is a 21-item, self-rated scale with a maximum score of 63 . Higher scores indicate greater symptom severity. The validity and reliability studies of the Turkish version of the BDI have been shown. ${ }^{34}$

The ESWT group received ESWT using Modus ESWT device (Serial No. 800-1520; Inceler Medical Ltd., Ankara, Turkey). A total of seven sessions of focused ESWT were performed with three days intervals. The ESWT was applied at MTrPs on the trapezius muscle at 500 pulses/trigger point, a total of 1500 to 4500 pulses/session 1.5 to 3 bars with H-ESWT $\left(0.26 \mathrm{~mJ} / \mathrm{mm}^{2}\right)$ in each session. The control group received traditional treatment modalities including HP, TENS, and US five times a week for two weeks. Continuous US at $1 \mathrm{Mhz}$ was applied at a dose of 1.5 watt $/ \mathrm{cm}^{2}$ for six minutes daily. In addition, TENS was applied for 30 minutes and HP was applied 20 minutes daily.

Trapezius stretching exercises were given to all patients in both groups. All patients were instructed about the exercises by physiotherapists and the first set of exercises were performed under the supervision of clinical physiotherapists. All patients were instructed to perform 10 repetitions of each exercise set. These exercises were performed three times a day for two weeks.

\section{Statistical analysis}

Statistical analysis was performed using the IBM SPSS version 22.0 software (IBM Corp., Armonk, NY, USA). Descriptive data were expressed in mean $\pm \mathrm{SD}$, or number and frequency. The Shapiro-Wilk test was used for normality test of data. For quantitative variables, the Student's t-test was used to compare normally distributed data between the groups, while the Mann-Whitney U test was used to compare nonnormally distributed data between the groups. For intra-group comparison, a paired sample t-test was performed to analyze normally distributed data, while the Wilcoxon signed-rank test was used to analyze non-normally distributed data. The Pearson's correlation analysis was performed to analyze possible correlations between the 
variables. A $p$ value of $<0.05$ was considered statistically significant.

\section{RESULTS}

Of a total of 94 patients, 49 (52.1\%) were included in the ESWT group and 45 (47.9\%) were included in the control group. Baseline demographic characteristics of the patients are shown in Table 1.

There was no statistically significant difference in the baseline VAS and SF-36 subscale scores between the groups ( $p>0.05)$. However, there was a statistically significant decrease in the VAS scores one month after treatment in both ESWT and control groups, compared to baseline scores $(p<0.001)$, although the decrease was statistically significantly greater in the ESWT group $(p<0.001)$. In addition, there was a statistically significant increase in the SF-36 subscale scores one month after treatment in both ESWT and control groups $(p<0.001)$ with a statistically significantly greater increase in the ESWT group $(p<0.001)$. Preand post-treatment VAS and SF-36 scores in the ESWT and control groups are presented in Table 2, Figure 2.

There was no statistically significant difference in the baseline PSQI, FACIT, NDI, and BDI scores between the groups ( $p>0.05)$. However, there was a statistically significant decrease in the PSQI, FACIT, NDI, and BDI scores one month after treatment in both ESWT and control groups $(p<0.001)$. However, the decrease in the ESWT group was statistically significantly higher $(p<0.001)$. Pre- and post-treatment PSQI, BDI, NDI, and FACIT scores in the ESWT and control groups are presented in Table 3, Figures 3-6.

The correlation analysis revealed a strong, positive, and statistically significant relationship between the changes in the VAS scores and

Table 1. Baseline demographic characteristics of patients

\begin{tabular}{|c|c|c|c|c|c|c|c|c|c|c|c|c|}
\hline & \multicolumn{4}{|c|}{ ESWT group } & \multicolumn{4}{|c|}{ Control group } & \multicolumn{4}{|c|}{ Total } \\
\hline & $\mathrm{n}$ & $\%$ & Mean \pm SD & Range & $\mathrm{n}$ & $\%$ & Mean \pm SD & Range & $\mathrm{n}$ & $\%$ & Mean \pm SD & Range \\
\hline Age (year) & & & $45.0 \pm 12.0$ & $21-74$ & & & $43.3 \pm 11.9$ & $19-68$ & & & $44.2 \pm 11.9$ & $19-74$ \\
\hline \multicolumn{13}{|l|}{ Sex } \\
\hline Male & 7 & 14.3 & & & 9 & 20 & & & 16 & 17 & & \\
\hline Female & 42 & 85.7 & & & 36 & 80 & & & 78 & 83 & & \\
\hline \multicolumn{13}{|l|}{ Marital status } \\
\hline Married & 40 & 81.6 & & & 35 & 77.8 & & & 75 & 79.8 & & \\
\hline Single & 9 & 18.4 & & & 10 & 22.2 & & & 19 & 20.2 & & \\
\hline \multicolumn{13}{|l|}{ Smoking status } \\
\hline Smoker & 24 & 49 & & & 18 & 40 & & & 42 & 44.7 & & \\
\hline Non-smoker & 25 & 51 & & & 27 & 60 & & & 52 & 55.3 & & \\
\hline \multicolumn{13}{|l|}{ Education status } \\
\hline None & 0 & 0 & & & 1 & 2.2 & & & 1 & 1.1 & & \\
\hline Read and write & 6 & 12.2 & & & 6 & 13.3 & & & 12 & 12.8 & & \\
\hline Primary school & 22 & 44.9 & & & 23 & 51.1 & & & 45 & 47.9 & & \\
\hline Secondary school & 8 & 16.3 & & & 3 & 6.7 & & & 11 & 11.7 & & \\
\hline High school & 10 & 20.4 & & & 10 & 22.2 & & & 20 & 21.3 & & \\
\hline University & 3 & 6.1 & & & 2 & 4.4 & & & 5 & 5.3 & & \\
\hline \multicolumn{13}{|l|}{ Occupation } \\
\hline Housewife & 31 & 63.3 & & & 25 & 55.6 & & & 56 & 59.6 & & \\
\hline Retired & 2 & 4.1 & & & 1 & 2.2 & & & 3 & 3.2 & & \\
\hline Student & 1 & 2 & & & 0 & 0 & & & 1 & 1.1 & & \\
\hline Full-time & 11 & 22.4 & & & 14 & 31.1 & & & 25 & 26.6 & & \\
\hline Part-time & 4 & 8.2 & & & 5 & 11.1 & & & 9 & 9.6 & & \\
\hline
\end{tabular}


changes in the PSQI ( $\mathrm{r}=0.728), \mathrm{BDI}(\mathrm{r}=0.614)$, NDI $(\mathrm{r}=0.702)$, and FACIT $(\mathrm{r}=0.673)$ scores after the treatment in the ESWT group. In addition, there was a strong, negative, and statistically significant relationship between the changes in the SF-36 $\mathrm{PF}$ subscale scores and the changes in the PSQI $(\mathrm{r}=-0.621)$ scores after the treatment in the ESWT group. There was also a moderate, negative, and

Table 2. Comparison of VAS and SF-36 scores before and after treatment in ESWT and control groups

\begin{tabular}{|c|c|c|c|c|c|}
\hline & \multicolumn{2}{|c|}{ ESWT group } & \multicolumn{2}{|c|}{ Control group } & \multirow{2}{*}{$\frac{\text { Inter-group }}{p^{\dagger}}$} \\
\hline & Mean \pm SD & Range & Mean \pm SD & Range & \\
\hline \multicolumn{6}{|l|}{ VAS } \\
\hline Pre-treatment & $8.3 \pm 1.2$ & 8 & $8.1 \pm 1.3$ & 8 & 0.457 \\
\hline Post-treatment & $3.7 \pm 1.7$ & 4 & $6.5 \pm 1.2$ & 7 & $<0.001^{*}$ \\
\hline Pre-post-treatment $p \neq$ & \multicolumn{2}{|c|}{$<0.001^{*}$} & \multicolumn{2}{|c|}{$<0.001^{*}$} & \\
\hline \multicolumn{6}{|l|}{ SF-36 } \\
\hline \multicolumn{6}{|l|}{ PF } \\
\hline Pre-treatment & $33.5 \pm 6.2$ & 30 & $34.4 \pm 7.9$ & 30 & 0.464 \\
\hline Post-treatment & $62.4 \pm 13.3$ & 60 & $47 \pm 10.2$ & 45 & $<0.001^{*}$ \\
\hline Pre-post-treatment $p \neq$ & \multicolumn{2}{|c|}{$<0.001^{*}$} & \multicolumn{2}{|c|}{$<0.001^{*}$} & \\
\hline \multicolumn{6}{|l|}{ DPR } \\
\hline Pre-treatment & $33.2 \pm 11.9$ & 25 & $36.7 \pm 12.6$ & 25 & 0.167 \\
\hline Post-treatment & $70.4 \pm 16.7$ & 75 & $54.4 \pm 18.7$ & 50 & $<0.001^{*}$ \\
\hline Pre-post-treatment $p \neq$ & \multicolumn{2}{|c|}{$<0.001^{*}$} & \multicolumn{2}{|c|}{$<0.001^{*}$} & \\
\hline \multicolumn{6}{|l|}{ DER } \\
\hline Pre-treatment & $37.4 \pm 14.6$ & 33.3 & $39.3 \pm 21.7$ & 33.3 & 0.512 \\
\hline Post-treatment & $78.9 \pm 18.9$ & 66.7 & $56.3 \pm 19.9$ & 66.7 & $<0.001^{*}$ \\
\hline Pre-post-treatment $p \neq$ & \multicolumn{2}{|c|}{$<0.001^{*}$} & \multicolumn{2}{|c|}{$<0.001^{*}$} & \\
\hline \multicolumn{6}{|l|}{ VT } \\
\hline Pre-treatment & $30.2 \pm 5.3$ & 30 & $33.1 \pm 6.6$ & 35 & $0.027^{*}$ \\
\hline Post-treatment & $60.5 \pm 11.4$ & 65 & $42.6 \pm 8.4$ & 45 & $<0.001^{*}$ \\
\hline Pre-post-treatment $p^{\ddagger}$ & \multicolumn{2}{|c|}{$<0.001^{*}$} & \multicolumn{2}{|c|}{$<0.001^{*}$} & \\
\hline \multicolumn{6}{|l|}{$\mathrm{MH}$} \\
\hline Pre-treatment & $32.9 \pm 4.8$ & 32 & $32.6 \pm 6.8$ & 32 & 0.501 \\
\hline Post-treatment & $59.6 \pm 15.6$ & 60 & $41.1 \pm 10.8$ & 40 & $<0.001^{*}$ \\
\hline Pre-post-treatment $p \neq$ & \multicolumn{2}{|c|}{$<0.001^{*}$} & \multicolumn{2}{|c|}{$<0.001^{*}$} & \\
\hline \multicolumn{6}{|l|}{$\mathrm{SF}$} \\
\hline Pre-treatment & $30.6 \pm 8.5$ & 25 & $32.4 \pm 9.6$ & 32.5 & 0.372 \\
\hline Post-treatment & $59.1 \pm 12.5$ & 62.5 & $44.5 \pm 11.7$ & 37.5 & $<0.001^{*}$ \\
\hline Pre-post-treatment $p \neq$ & \multicolumn{2}{|c|}{$<0.001^{*}$} & \multicolumn{2}{|c|}{$<0.001^{*}$} & \\
\hline \multicolumn{6}{|l|}{$\mathrm{BP}$} \\
\hline Pre-treatment & $30.9 \pm 6.9$ & 32.5 & $32.7 \pm 8.5$ & 32.5 & 0.259 \\
\hline Post-treatment & $61.6 \pm 16.0$ & 62.5 & $45.5 \pm 11.7$ & 45 & $<0.001^{*}$ \\
\hline Pre-post-treatment $p \neq$ & $<0$ & & $<0$ & & \\
\hline $\mathrm{GH}$ & & & & & \\
\hline Pre-treatment & $29.0 \pm 6.5$ & 30 & $31 \pm 6.7$ & 30 & 0.239 \\
\hline Post-treatment & $55.6 \pm 13.1$ & 60 & $40 \pm 9.0$ & 40 & $<0.001^{*}$ \\
\hline Pre-post-treatment $p^{\ddagger}$ & $<0$ & & $<0$ & & \\
\hline
\end{tabular}

VAS: Visual analog scale; SF-36: Short form-36; ESWT: Extracorporeal shock wave therapy; SD: Standard deviation; PF: Physical functioning; DPR: Difficulty in physical role; DER: Difficulty in emotional role; VT: Vitality; MH: Mental health; SF: Social functioning; BP: Bodily pain; GH: General health; † Mann-Whitney U test; $¥$ Wilcoxon signed-rank test; " $p<0.05$. 


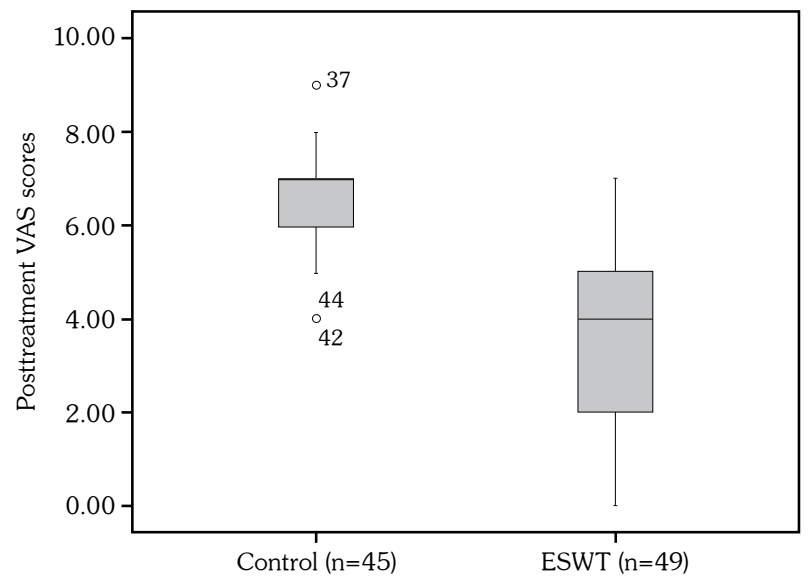

Figure 2. Differences of VAS values between ESWT and control groups after treatment.

VAS: Visual analog scale; ESWT: Extracorporeal shock wave therapy.

statistically significant relationship between the changes in the SF-36 PF and the changes in the BDI $(\mathrm{r}=-0.512)$ scores after the treatment in the ESWT group. In the control group, there was a moderate, positive, and statistically significant relationship between the changes in the SF-36 $\mathrm{PF}$ and the changes in the BDI $(\mathrm{r}=0.424)$ scores. The results of the correlation analysis of all scales in the ESWT and control groups are summarized in Table 4.

\section{DISCUSSION}

In the present study, we investigated the effects of ESWT and conventional physical therapy modalities such as US, TENS, and HP on QoL, sleep, mental health, neck disability, and fatigue in MPS patients.

The main goal of MPS treatment is to break the vicious cycle of pain-spasm-pain through the elimination of trigger points. For this purpose, thermal and/or mechanical effects of HP, TENS, and US are used. ${ }^{27}$ Due to the thermogenic effects of US, elasticity of the collagen tissue and blood flow temporarily increase, contributing to the broken vicious cycle of pain and muscular spasm. ${ }^{35}$ In addition, non-thermal effects of US provide muscular analgesia which can be attributed to decreased nociceptive input to the central nervous system. ${ }^{36}$

In general, the effect of ESWT on tissues can be explained by the mechanotransduction.

\begin{tabular}{|c|c|c|c|}
\hline & ESWT group & Control group & Inter-group \\
\hline & Mean \pm SD & Mean \pm SD & $p \dagger$ \\
\hline \multicolumn{4}{|l|}{ PSQI } \\
\hline Pre-treatment & $15.5 \pm 1.9$ & $15.1 \pm 2.1$ & 0.386 \\
\hline Post-treatment & $8.2 \pm 2.4$ & $11.8 \pm 2.0$ & $<0.001^{*}$ \\
\hline Pre-post-treatment $p \neq$ & $<0.001^{*}$ & $<0.001^{*}$ & \\
\hline \multicolumn{4}{|l|}{ BDI } \\
\hline Pre-treatment & $12.4 \pm 2.8$ & $11.4 \pm 4.7$ & 0.234 \\
\hline Post-treatment & $5.7 \pm 1.9$ & $8.9 \pm 3.6$ & $<0.001^{*}$ \\
\hline Pre-post-treatment $p \neq$ & $<0.001^{*}$ & $<0.001^{*}$ & \\
\hline \multicolumn{4}{|l|}{ NDI } \\
\hline Pre-treatment & $45.6 \pm 7.8$ & $43.5 \pm 7.3$ & 0.171 \\
\hline Post-treatment & $22.2 \pm 7.8$ & $33.5 \pm 6.6$ & $<0.001^{*}$ \\
\hline Pre-post-treatment $p \neq$ & $<0.001^{*}$ & $<0.001^{*}$ & \\
\hline \multicolumn{4}{|l|}{ FACIT } \\
\hline Pre-treatment & $25.6 \pm 4.2$ & $24.3 \pm 2.8$ & 0.075 \\
\hline Post-treatment & $11.4 \pm 3.8$ & $18.7 \pm 3.0$ & $<0.001^{*}$ \\
\hline Pre-post-treatment $p \neq$ & $<0.001^{*}$ & $<0.001^{*}$ & \\
\hline \multicolumn{4}{|c|}{$\begin{array}{l}\text { PSQI: Pittsburgh Sleep Quality Index; BDI: Beck Depression Inventory; NDI: Neck Disability Index; FACIT: } \\
\text { Functional Assessment of Chronic Illness Therapy-Fatigue Scale; ESWT: Extracorporeal shock wave } \\
\text { therapy; SD: Standard deviation; † Student t-test; † Paired sample t-test; * } \mathrm{p}<0.05 \text {. }\end{array}$} \\
\hline
\end{tabular}




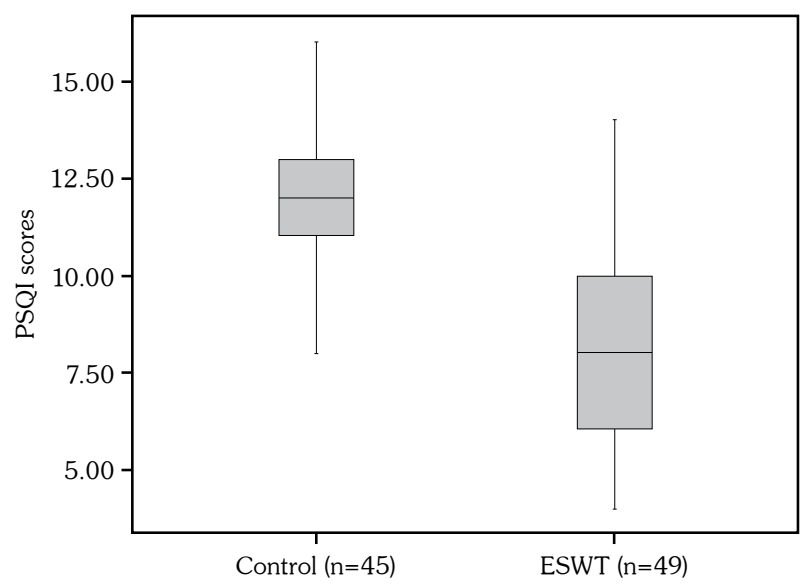

Figure 3. Differences of PSQI values between ESWT and control groups after treatment.

PSQI: Pittsburgh Sleep Quality Index; ESWT: Extracorporeal shock wave therapy.

Through this mechanism, ESWT acting as a mechanical stimulus enhances biological healing processes where mechanotransduction converts physical forces into biomechanical signals which are later integrated into cellular responses. ${ }^{37}$ Although the exact mechanism of ESWT has not been clearly elucidated yet, several proposals have been made. In a study, ESWT was shown to prevent overstimulation of the nerves and nociceptors and to increase the blood flow, leading to pain relief through reduced muscle spasms and stiffness. ${ }^{37}$ In another study, ESWT reduced musculoskeletal pain by disrupting

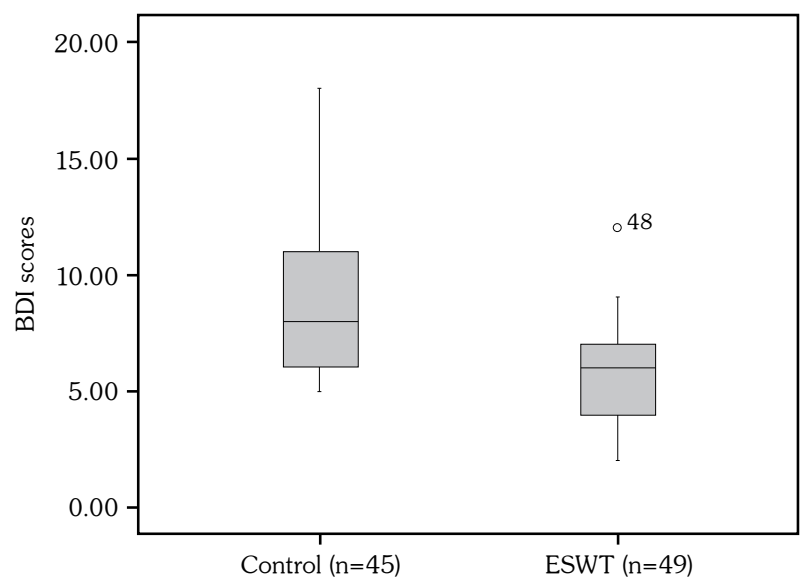

Figure 4. Differences of BDI values between ESWT and control groups after treatment.

BDI: Beck Depression Inventory; ESWT: Extracorporeal shock wave therapy.

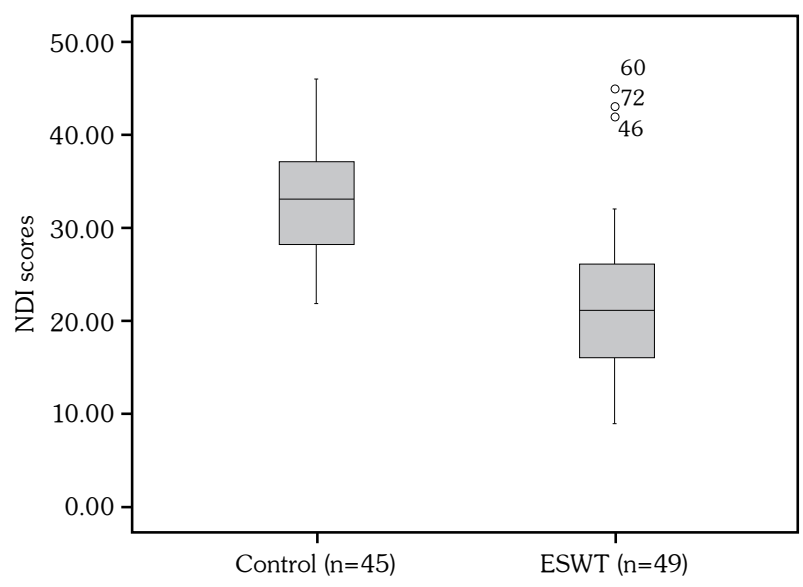

Figure 5. Differences of NDI values between ESWT and control groups after treatment.

NDI: Neck Disability Index; ESWT: Extracorporeal shock wave therapy.

the non-myelinated fibers and decreasing the production of substance $\mathrm{P}$ level at the dorsal root ganglia. ${ }^{38,39}$

To date, several clinical studies have proven the positive effects of US on MPS. In their study including 55 patients, Dundar et al. ${ }^{40}$ reported that US treatment for 15 days yielded statistically significant improvements in pain, disability, and QoL. In addition, Srbely et al. ${ }^{41}$ and Aguilera et al. ${ }^{42}$ confirmed improved pain relief in patients with MPS. In another study, Ay et al. ${ }^{43}$ divided the patients with MPS into three groups and found statistically significant improvements in pain and

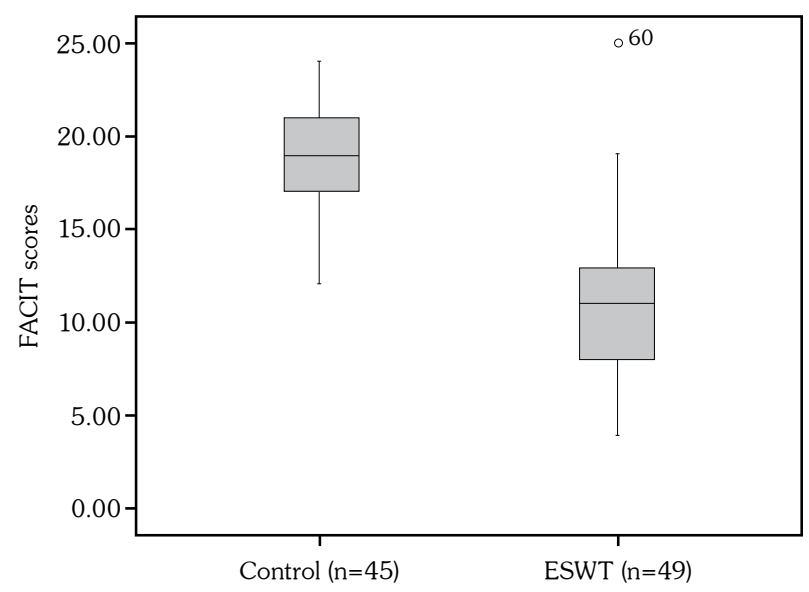

Figure 6. Differences of FACIT values between ESWT and control groups after treatment.

FACIT: Functional Assessment of Chronic Illness Therapy; ESWT: Extracorporeal shock wave therapy. 
Table 4. Correlation analysis of VAS and SF-36 scores with PSQI, BDI, NDI and FACIT scores one month after treatment in ESWT and control groups.

\begin{tabular}{|c|c|c|c|c|c|}
\hline Group & $\begin{array}{l}\text { At one month } \\
\text { post-treatment }\end{array}$ & PSQI & BDI & NDI & FACIT \\
\hline \multirow[t]{27}{*}{ ESWT } & VAS & & & & \\
\hline & $r$ & 0.728 & 0.614 & 0.702 & 0.673 \\
\hline & $\mathrm{p}$ & $<0.001^{*}$ & $<0.001^{*}$ & $<0.001^{*}$ & $<0.001^{*}$ \\
\hline & SF-36 PF & & & & \\
\hline & r & -0.621 & -0.512 & -0.304 & -0.305 \\
\hline & $\mathrm{p}$ & $<0.001^{*}$ & $<0.001^{*}$ & $0.034^{*}$ & $0.033^{*}$ \\
\hline & SF-36 DPR & & & & \\
\hline & r & -0.511 & -0.404 & -0.397 & -0.325 \\
\hline & $\mathrm{p}$ & $<0.001^{*}$ & $0.004^{*}$ & $0.005^{*}$ & $0.023^{*}$ \\
\hline & SF-36 DER & & & & \\
\hline & r & -0.479 & -0.431 & -0.394 & -0.411 \\
\hline & $\mathrm{p}$ & $<0.001^{*}$ & $0.002^{*}$ & $0.005^{*}$ & $0.003^{*}$ \\
\hline & SF-36 VT & & & & \\
\hline & r & -0.646 & -0.516 & -0.487 & -0.565 \\
\hline & $\mathrm{p}$ & $<0.001^{*}$ & $<0.001^{*}$ & $<0.001^{*}$ & $<0.001^{*}$ \\
\hline & SF-36 MH & & & & \\
\hline & r & -0.742 & -0.602 & -0.565 & -0.527 \\
\hline & $\mathrm{p}$ & $<0.001^{*}$ & $<0.001^{*}$ & $<0.001^{*}$ & $<0.001^{*}$ \\
\hline & SF-36 SF & & & & \\
\hline & r & -0.586 & -0.522 & -0.480 & -0.560 \\
\hline & $\mathrm{p}$ & $<0.001^{*}$ & $<0.001^{*}$ & $<0.001^{*}$ & $<0.001^{*}$ \\
\hline & SF-36 BP & & & & \\
\hline & r & -0.686 & -0.506 & -0.665 & -0.609 \\
\hline & $\mathrm{p}$ & $<0.001^{*}$ & $<0.001^{*}$ & $<0.001^{*}$ & $<0.001^{*}$ \\
\hline & SF-36 GH & & & & \\
\hline & r & -0.737 & -0.604 & -0.595 & -0.552 \\
\hline & $\mathrm{p}$ & $<0.001^{*}$ & $<0.001^{*}$ & $<0.001^{*}$ & $<0.001^{*}$ \\
\hline \multirow[t]{27}{*}{ Control } & VAS & & & & \\
\hline & r & 0.176 & 0.220 & 0.386 & 0.285 \\
\hline & $\mathrm{p}$ & 0.249 & 0.147 & $0.009^{*}$ & 0.057 \\
\hline & SF-36 PF & & & & \\
\hline & r & 0.230 & 0.424 & 0.094 & -0.081 \\
\hline & $\mathrm{p}$ & 0.128 & $0.004^{*}$ & 0.538 & 0.599 \\
\hline & SF-36 DPR & & & & \\
\hline & r & -0.011 & -0.002 & -0.211 & -0.180 \\
\hline & $\mathrm{p}$ & 0.941 & 0.987 & 0.163 & 0.237 \\
\hline & SF-36 DER & & & & \\
\hline & r & -0.154 & -0.109 & -0.246 & -0.314 \\
\hline & $\mathrm{p}$ & 0.312 & 0.477 & 0.103 & $0.036^{*}$ \\
\hline & SF-36 VT & & & & \\
\hline & r & -0.229 & -0.199 & -0.139 & -0.149 \\
\hline & $\mathrm{p}$ & 0.130 & 0.191 & 0.363 & 0.327 \\
\hline & SF-36 MH & & & & \\
\hline & r & -0.340 & -0.095 & -0.175 & -0.136 \\
\hline & $\mathrm{p}$ & $0.022^{*}$ & 0.536 & 0.250 & 0.373 \\
\hline & SF-36 SF & & & & \\
\hline & r & -0.302 & -0.066 & -0.394 & -0.166 \\
\hline & $\mathrm{p}$ & $0.043^{*}$ & 0.665 & $0.007^{*}$ & 0.276 \\
\hline & SF-36 BP & & & & \\
\hline & r & -0.402 & -0.22 & -0.103 & -0.077 \\
\hline & $\mathrm{p}$ & $0.006^{*}$ & 0.146 & 0.499 & 0.613 \\
\hline & SF-36 GH & & & & \\
\hline & r & -0.250 & -0.137 & -0.150 & -0.107 \\
\hline & $\mathrm{p}$ & 0.097 & 0.368 & 0.325 & 0.485 \\
\hline
\end{tabular}


disability in both the US and phonophoresis groups. Similarly, in a study conducted by Ilter et al., ${ }^{44}$ a total of 60 patients with MPS were divided into three groups and statistically significant improvements were shown in pain, BDI, NDI, and Nottingham Heath Profile scores in the US group. In another study involving 59 patients with MPS, Kavadar et al. ${ }^{45}$ found a statistically significant improvement in pain and BDI scores. Moreover, Yildirim et al. ${ }^{46}$ divided 54 patients into two groups and one group received 10 sessions of US treatment and the other group received 10 sessions of placebo US treatment. The authors found a decline in pain scores which was statistically significantly higher in the US group, although there was no statistically significant difference in the BDI scores between two groups.

Furthermore, there is a growing number of studies demonstrating that TENS yields pain relief in patients with MPS. ${ }^{47-49}$ In our study, we found a statistically significant improvement in pain, SF-36, PSQI, FACIT, BDI, and NDI in the HP, TENS, and US group after treatment. These findings suggest that combined traditional physical therapy modalities are more effective in the treatment of MPS compared to individual applications.

In the literature, the ESWT is used at three energy intensity levels: (i) low-energy flux density $\left(\mathrm{EFD}<0.08 \mathrm{~mJ} / \mathrm{mm}^{2}\right.$ ); (ii) medium-energy flux density (EFD 0.08-0.28 $\mathrm{mJ} / \mathrm{mm}^{2}$ ); (iii) highenergy flux density (EFD $\left.>0.28 \mathrm{~mJ} / \mathrm{mm}^{2}\right)^{50-52}$ The total amount of energy and density is still discussed by the researchers, and no consensus has yet been reached. ${ }^{53,54}$ Of note, $\mathrm{H}$-ESWT may cause side effects such as permanent tendon damage, whereas low-EFD ESTW (L-ESWT) has a lower therapeutic effect. ${ }^{55}$ In our study, none of the patients experienced such side effects.

In a study conducted by Müller-Ehrenberg and Licht, ${ }^{56}$ focused H-ESWT was used in MPS patients and decreased VAS scores were achieved at three months. In another study, Jeon et al. ${ }^{22}$ divided patients into two groups as ESWT and TENS-TPI groups and used focused L-ESWT in the ESWT group for three sessions. The authors found pain relief in both groups, although it did not reach statistical significance. Similarly, Ji et al. ${ }^{23}$ used focused L-ESWT for four sessions in MPS patients and found ESWT to be an effective therapeutic modality with reduced VAS scores and pain threshold (PT). In another study, Cho et al. ${ }^{55}$ used combined therapy as radial L-ESWT for 12 sessions and stabilization shoulder exercise and found greater improvements in pain and functional scores with combined therapy. In addition, Gur et al. ${ }^{21}$ used focused H-ESWT and compared three sessions with a single session of therapy. The authors found that three sessions of therapy improved pain compared to a single-session therapy. Consistent with these findings, Akturk et al. ${ }^{29}$ divided 60 MPS patients into three groups and used L-ESWT for four sessions. They found a statistically significant improvement in pain and SF-36 subscale scores in the ESWT and US groups; however, there was no statistically significant difference in the anxiety and depression scores after treatment. Hong et al. ${ }^{57}$ also compared ESWT and TPI and used focused L-ESWT for three sessions. The authors found ESWT therapy to be more effective than TPI treatment in terms of pain relief; however, there was no statistically significant difference in disability between the groups. In another study, Park et al. ${ }^{58}$ compared H-ESWT and L-ESWT and found improvements in the Verbal Numerical Pain Scale, NDI, neck range of motion (neck ROM), and PT in both groups; however, there was no statistically significant difference in the neck ROM and NDI scores between the groups.

Considering all these findings, the increase in the number of sessions of ESWT treatment and its use in high-energy density may increase its efficacy on pain disability and functional status. Therefore, we used H-ESWT for seven sessions in our patients. In the present study, we found statistically significant improvements in the SF-36, PSQI, FACIT, NDI, and BDI scores and pain relief in our patients with MPS after treatment. Improvements in all these scales indicate the importance of H-ESWT for a high number of sessions in pain management in patients with MPS. In the aforementioned studies, the authors found similar results for pain, QoL, and disability in the US, TPI groups and ESWT groups. This can be attributed to the fact that, in previous studies, L-ESWT was used for fewer sessions. In the present study, the statistically significant results in the ESWT group compared to combined physical therapy group can be explained by the fact that we applied a higher number of sessions of H-ESWT in our MPS patients. 
Moreover, in the present study, we found a significant correlation between the VAS and SF-36 subscale scores and the PSQI, BDI, NDI and FACIT scores, compared to the control group. This finding indicates that H-ESWT for a high number of sessions can be a more effective non-invasive treatment modality than combined physical therapy methods.

Nonetheless, there are some limitations to this study. The presence of a non-treatment group and a larger sample size would increase the power of results. We, therefore, recommend further largescale, long-term studies to confirm these findings and to establish a definite conclusion.

In conclusion, pain management is the mainstay of treatment which is associated with decreased pain and improved QoL, sleep, depression, fatigue, and disability in patients with MPS. Based on our study results, we suggest that H-ESWT for a high number of sessions is effective than traditional physical therapy methods in patients with MPS.

\section{Declaration of conflicting interests}

The authors declared no conflicts of interest with respect to the authorship and/or publication of this article.

\section{Funding}

The authors received no financial support for the research and/or authorship of this article.

\section{REFERENCES}

1. Simons DG, Travell J. Myofascial trigger points, a possible explanation. Pain 1981;10:106-9.

2. Novikova LB, Akopyan AP. Myofascial pain syndrome. Zh Nevrol Psikhiatr Im S S Korsakova 2015;115:21-4. [Abstract]

3. Sciotti VM, Mittak VL, DiMarco L, Ford LM, Plezbert $\mathrm{J}$, Santipadri E, et al. Clinical precision of myofascial trigger point location in the trapezius muscle. Pain 2001;93:259-66.

4. Wade SW, Strader C, Fitzpatrick LA, Anthony MS. Sex- and age-specific incidence of non-traumatic fractures in selected industrialized countries. Arch Osteoporos 2012;7:219-27.

5. Fischer AA. Pressure algometry over normal muscles. Standard values, validity and reproducibility of pressure threshold. Pain 1987;30:115-26.

6. Simons DG, Travell JG, Simons LS, editors. Myofascial pain and dysfunction: upper half of body. 2nd ed. Baltimore: Lippincott Williams \& Wilkins; 1999.
7. Sabatke S, Scola RH, Paiva ES, Kowacs PA. Injecction of trigger points in the temporal muscles of patients with miofascial syndrome. Arq Neuropsiquiatr 2015;73:861-6.

8. Borg-Stein J, Simons DG. Focused review: myofascial pain. Arch Phys Med Rehabil 2002;83:40-7.

9. Bennett R. Myofascial pain syndromes and their evaluation. Best Pract Res Clin Rheumatol 2007;21:427-45.

10. De las Penas CF, Campo MS, Carnero JF, Miangolarra Page JC. Manual therapies in myofascial trigger point treatment: A systematic review. J Bodyw Mov Ther 2005;9:27-34.

11. Rickards LD. The effectiveness of non-invasive treatments for active myofascial trigger point pain: a systematic review of the literature. Int $\mathrm{J}$ Osteopath Med 2006;9:120-36.

12. Simons DG. Myofascial pain and dysfunction syndrome. J Muscoskel Pain 1993;1:123-32.

13. Tough EA, White AR, Cummings TM, Richards $\mathrm{SH}$, Campbell JL. Acupuncture and dry needling in the management of myofascial trigger point pain: a systematic review and meta-analysis of randomised controlled trials. Eur J Pain 2009;13:3-10.

14. Lavelle ED, Lavelle W, Smith HS. Myofascial trigger points. Med Clin North Am 2007;91:229-39.

15. van der Windt DA, van der Heijden GJ, van den Berg SG, ter Riet G, de Winter AF, Bouter LM. Ultrasound therapy for musculoskeletal disorders: a systematic review. Pain 1999;81:257-71.

16. Pan PJ, Chou CL, Chiou HJ, Ma HL, Lee HC, Chan RC. Extracorporeal shock wave therapy for chronic calcific tendinitis of the shoulders: a functional and sonographic study. Arch Phys Med Rehabil 2003;84:988-93.

17. Perlick L, Schiffmann R, Kraft CN, Wallny T, Diedrich O. Extracorporal shock wave treatment of the achilles tendinitis: Experimental and preliminary clinical results. Z Orthop Ihre Grenzgeb 2002;140:275-80. [Abstract]

18. Ordahan B, Türkoğlu G, Karahan AY, Akkurt HE. Extracorporeal shockwave therapy versus kinesiology taping in the management of plantar fasciitis: a randomized clinical trial. Arch Rheumatol 2017;32:227-33.

19. Rompe JD, Rumler F, Hopf C, Nafe B, Heine J. Extracorporal shock wave therapy for calcifying tendinitis of the shoulder. Clin Orthop Relat Res 1995;321:196-201.

20. Gleitz M. Trigger shockwave therapy with radial and focused shockwaves. Current Status Orthop 2006;5:303-12.

21. Gür A, Koca İ, Karagüllü H, Altındağ Ö, Madenci E, Tutoğlu A, et al. Comparision of the effectiveness of two different extracorporeal shockwave therapy regimens in the treatment of patients with myofascial pain syndrome. Arch Rheumatol 2014;29:186-93.

22. Jeon JH, Jung YJ, Lee JY, Choi JS, Mun JH, Park WY, et al. The effect of extracorporeal shock wave 
therapy on myofascial pain syndrome. Ann Rehabil Med 2012;36:665-74.

23. Ji HM, Kim HJ, Han SJ. Extracorporeal shock wave therapy in myofascial pain syndrome of upper trapezius. Ann Rehabil Med 2012;36:675-80.

24. Ramon S, Gleitz M, Hernandez L, Romero LD. Update on the efficacy of extracorporeal shockwave treatment for myofascial pain syndrome and fibromyalgia. Int $\mathrm{J}$ Surg 2015;24:201-6.

25. Ottomann C, Hartmann B, Tyler J, Maier H, Thiele $\mathrm{R}$, Schaden $\mathrm{W}$, et al. Prospective randomized trial of accelerated re-epithelization of skin graft donor sites using extracorporeal shock wave therapy. J Am Coll Surg 2010;211:361-7.

26. Rompe JD, Hope C, Küllmer K, Heine J, Bürger R. Analgesic effect of extracorporeal shock-wave therapy on chronic tennis elbow. J Bone Joint Surg [Br] 1996;78:233-7.

27. Travell JG, Simons DG, editors. Myofascial pain and dysfunction. The trigger point manual. Baltimore: Williams and Wilkins; 1992.28. Gallagher EJ, Liebman M, Bijur PE. Prospective validity of clinically important changes in pain severity measured on visual analog scale. Ann Emerg Med 2001;38:633-8.

28. Gallagher EJ, Liebman M, Bijur PE. Prospective validation of clinically important changes in pain severity measured on a visual analog scale. Ann Emerg Med 2001;38:633-8.

29. Aktürk S, Kaya A, Çetintaş D, Akgöl G, Gülkesen A, Kal GA, et al. Comparision of the effectiveness of ESWT and ultrasound treatments in myofascial pain syndrome: randomized, sham-controlled study. J Phys Ther Sci 2018;30:448-53.

30. Koçyiğit H, Aydemir Ö, Fişek G, Ölmez N, Memiş A. Reliability and validity of the Turkish Version of Short Form-36. İlaç ve Tedavisi Dergisi 1999;2:12.

31. Ağargün MY, Kara $\mathrm{H}$, Anlar Ö. The Validity and reliability of the Pittsburgh Sleep Quality Index. Turkish Journal of Phschiatry 1996;7:2.

32. Çinar D, Yava A. Validity and reliability of functional assessment of chronic illness treatment-fatigue scale in Turkish patients with type 2 diabetes. Endocrinol Diabetes Nutr 2018;65:409-17.

33. Aslan E, Karaduman A, Yakut Y, Aras B, Simsek IE, Yaglı N. The cultural adaptation, reliability and validity of neck disability index in patients with neck pain: a Turkish version study. Spine (Phila Pa 1976) 2008;33:362-5.

34. Sahin NH. Use of the Beck Depression Inventory with Turkish University Students: Reliability, validity and Factor Analysis. Turkish Journal of Psychology 1989;7:3-13.

35. Ultrasound therapy with local injection in the treatment of active myofascial trigger points of the upper trapezius muscle. Arch Phys Med Rehabil 2011;92:657-62.

36. Gonçalves MC, Teixeira da Silva EG, Chaves TC, Dach F, Speciali JG. Static ultrasound and manual therapy in refractory migraine. Case report Rev Dor Sao Paulo 2012;13:80-4.

37. Zimmermann R, Cumpanas A, Miclea F, Janetschek G. Extracorporeal shock wave therapy for the treatment of chronic pelvic pain syndrome in males: a randomised, double-blind, placebo-controlled study. Eur Urol 2009;56:418-24.

38. Hausdorf J, Lemmens MA, Heck KD, Grolms N, Korr $\mathrm{H}$, Kertschanska $\mathrm{S}$, et al. Selective loss of unmyelinated nerve fibers after extracorporeal shockwave application to the musculoskeletal system. Neuroscience 2008;155:138-44.

39. Hausdorf J, Lemmens MA, Kaplan S, Marangoz C, Milz S, Odaci E, et al. Extracorporeal shock wave application to the distal femur of rabbits diminishes the number of neurons immunoreactive for substance P in dorsal root ganglia L5. Brain Res 2008;1207:96-101.

40. Dündar Ü, Solak Ö, Şamli F, Kavuncu V. Effectiveness of ultrasound therapy in cervical myofascial pain syndrome: a double blind, placebo-controlled study. Arch Rheumatol 2010;25:110-15.

41. Srbely JZ, Dickey JP, Lowerison M, Edwards AM, Nolet PS, Wong LL. Stimulation of myofascial trigger points with ultrasound induces segmental antinociceptive effects: a randomized controlled study. Pain 2008;139:260-6.

42. Aguilera FJ, Martín DP, Masanet RA, Botella AC, Soler LB, Morell FB. Immediate effect of ultrasound and ischemic compression techniques for the treatment of trapezius latent myofascial trigger points in healthy subjects: a randomized controlled study. J Manipulative Physiol Ther 2009;32:515-20.

43. Ay S, Doğan SK, Evcik D, Başer OC. Comparison the efficacy of phonophoresis and ultrasound therapy in myofascial pain syndrome. Rheumatol Int 2011;31:1203-8.

44. Ilter L, Dilek B, Batmaz I, Ulu MA, Sariyildiz MA, Nas K, et al. Efficacy of Pulsed and Continuous Therapeutic Ultrasound in Myofascial Pain Syndrome: A Randomized Controlled Study. Am J Phys Med Rehabil 2015;94:547-54.

45. Kavadar G, Çağlar N, Özen Ş, Tütün Ş, Demircioğlu D. Efficacy of conventional ultrasound therapy on myofascial pain syndrome: a placebo controlled study. Agri 2015;27:190-6.

46. Yildirim MA, Öneș K, Gökșenoğlu G. Effectiveness of ultrasound therapy on myofascial pain syndrome of the upper trapezius: randomized, single-blind, placebocontrolled study. Arch Rheumatol 2018;33:418-23.

47. Azatcam G, Atalay NS, Akkaya N, Sahin F, Aksoy $\mathrm{S}$, Zincir $\mathrm{O}$, et al. Comparison of effectiveness of transcutaneous electrical nerve stimulation and kinesio taping added to exercises in patients with myofascial pain syndrome. J Back Musculoskelet Rehabil 2017;30:291-8.

48. Dissanayaka TD, Pallegama RW, Suraweera HJ, Johnson MI, Kariyawasam AP. Comparison of 
the effectiveness of transcutaneous electrical nerve stimulation and interferential therapy on the upper trapezius in myofascial pain syndrome: a randomized controlled study. Am J Phys Med Rehabil 2016;95:663-72.

49. Takla MKN. Low-frequency high-intensity versus medium-frequency low-intensity combined therapy in the management of active myofascial trigger points: A randomized controlled trial. Physiother Res Int 2018;23:e1737.

50. Rompe JD, Furia J, Weil L, Maffulli N. Shock wave therapy for chronic plantar fasciopathy. Br Med Bull 2007;81:183-208.

51. Gollwitzer H, Diehl P, von Korff A, Rahlfs VW, Gerdesmeyer L. Extracorporeal shock wave therapy for chronic painful heel syndrome: a prospective, double blind, randomized trial assessing the efficacy of a new electromagnetic shock wave device. J Foot Ankle Surg 2007;46:348-57.

52. Liang HW, Wang TG, Chen WS, Hou SM. Thinner plantar fascia predicts decreased pain after extracorporeal shock wave therapy. Clin Orthop Relat Res 2007;460:219-25.

53. Chow IH, Cheing GL. Comparison of different energy densities of extracorporeal shock wave therapy (ESWT) for the management of chronic heel pain. Clin Rehabil 2007;21:131-41.

54. Thiel M. Application of shock waves in medicine. Clin Orthop Relat Res 2001;387:18-21.

55. Cho YS, Park SJ, Jang SH, Choi YC, Lee $\mathrm{JH}$, Kim JS. Effects of combined treatment of extracorporeal shock wave therapy (ESWT) and stabilisation exercises on pain and functions of patients with myofascial pain syndrome. J Phys Ther Sci 2012;24:1319-23.

56. Müller-Ehrenberg H, Licht G. Diagnosis and therapy of myofascial pain syndrome with focused shock waves (ESWT) Med Orthop Tech 2005;5:1-6.

57. Hong JO, Park JS, Jeon DG, Yoon WH, Park JH. Extracorporeal Shock Wave Therapy Versus Trigger Point Injection in the Treatment of Myofascial Pain Syndrome in the Quadratus Lumborum. Ann Rehabil Med 2017;41:582-8.

58. Park KD, Lee WY, Park MH, Ahn JK, Park Y. Highversus low-energy extracorporeal shock-wave therapy for myofascial pain syndrome of upper trapezius: A prospective randomized single blinded pilot study. Medicine (Baltimore) 2018;97:e11432. 